\title{
Evaluation of seven DNA barcodes for differentiating closely related medicinal Gentiana species and their adulterants
}

Ka-Lok Wong ${ }^{1}$, Paul Pui-Hay But ${ }^{2}$ and Pang-Chui Shaw ${ }^{1,2^{*}}$

\begin{abstract}
Background: Species identification of living organisms by standard DNA sequences has been well-accepted. Consortium for the Barcode of Life $(\mathrm{CBOL})$ recommends chloroplast regions rbcL and matK as the DNA barcodes for the land plants. This study aims to evaluate the feasibility and limitations of $r b c L$, matK, and 5 other commonly used regions as the DNA barcodes for the medicinal Gentiana and their adulterants, Gentiana. rhodantha and Podophyllum hexandrum.

Methods: The species differentiation power of rbcL, matK, nuclear internal transcribed spacer (ITS) and $5 \mathrm{~S}$ rRNA intergenic spacer, and chloroplast trnH-psbA, trnL-F and rp/36-rps8 intergenic spacers were tested in different medicinal Gentiana, including Gentiana scabra, Gentiana triflora, Gentiana manshurica and Gentiana rigescens, from common adulterants such as Gentiana rhodantha and Podophyllum hexandrum (a toxic herb producing podophyllotoxin).
\end{abstract}

Results: All seven tested loci could be used to differentiate medicinal Gentiana species from their adulterants, and to distinguish Guanlongdan from Jianlongdan. In terms of general differentiation powers, rbcL and matK had no significant advantages over the other five loci. Only the 5 S rRNA and trnL-F intergenic spacers were able to discriminate the closely related species G. triflora, G. scabra and G. manshurica.

Conclusion: The DNA barcodes $r b c L$ and matK are useful in differentiation of closely related medicinal species of Gentiana, but had no significant advantages over the other five tested loci.

\section{Background}

The nuclear and chloroplast genomes are the major targets for plant species authentication and phylogenetic studies. Since the rate of evolution varies across each genome, different DNA regions may be selected to reveal different taxonomic levels. The criteria for a useful DNA marker for authentication are: (1) high interspecific divergence; (2) low intraspecific divergence; (3) short PCR product of around $1 \mathrm{~kb}$; and (4) availability of universal primers for amplification [1,2]. The Consortium for the Barcode of Life (CBOL) set up a standardized sampling method and experimental protocol to

\footnotetext{
* Correspondence: pcshaw@cuhk.edu.hk

'State Key Laboratory of Phytochemistry and Plant Resources in West China (CUHK), Institute of Chinese Medicine, The Chinese University of Hong Kong, Shatin, Hong Kong, China

${ }^{2}$ School of Life Sciences, The Chinese University of Hong Kong, Shatin, Hong Kong, China
}

\section{Biomed Central}

(c) 2013 Wong et al.; licensee BioMed Central Ltd. This is an Open Access article distributed under the terms of the Creative Commons Attribution License (http://creativecommons.org/licenses/by/2.0), which permits unrestricted use, distribution, and reproduction in any medium, provided the original work is properly cited. analyze agreed-upon "DNA barcodes" [3]. This universal identification system is called DNA barcoding. Recently, the CBOL Plant Working Group recommended that $r b c L$ and $m a t K$ should be used as the land plant barcodes [4]. The former offers high universality and good discrimination power, while the latter has higher resolution than other loci. However, it is known that the differentiation powers of $r b c L$ and matK may not be sufficient for closely related species [5]. Indeed, plenty of land plants are identified by other DNA regions as markers.

The internal transcribed spacer (ITS) of the nuclear ribosomal cistron consists of ITS1 and ITS 2, and has been demonstrated to be useful for phylogenic studies in many angiosperm families [6]. Recently, over 60,000 ITS sequences of plants and animals from GenBank were compared [7]. At the species level, the success rates of identification were $91.9 \%, 76.1 \%, 74.2 \%, 67.1 \%, 88.1 \%$ and $77.4 \%$ for animals, dicotyledons, monocotyledons, 
Table 1 Samples studied

\begin{tabular}{|c|c|c|c|c|c|c|c|c|c|c|c|}
\hline \multirow[t]{2}{*}{ No. } & \multirow[t]{2}{*}{ Scientific name } & \multirow[t]{2}{*}{ TCM name } & \multirow[t]{2}{*}{ Voucher / collection place } & \multirow[t]{2}{*}{ Voucher } & \multicolumn{7}{|c|}{ GenBank accession number } \\
\hline & & & & & $r b c L$ & matK & $\operatorname{trnH}-p s b A$ & $t r n L-F$ & rp/36-rps8 & ITS & 5S rRNA \\
\hline \multirow[t]{3}{*}{1} & G. manshurica & Guanlongdan (GL) & Jilin city, Jilin & $2005-2701 C$ & JN162107 & JN162097 & GQ864029 & GQ864090 & GQ864078 & GQ864017 & Clone 2: GQ864046 \\
\hline & & & & & & & & & & & Clone 3: GQ864047 \\
\hline & & & & & & & & & & & Clone 4: GQ864048 \\
\hline \multirow[t]{3}{*}{2} & G. manshurica & $\mathrm{GL}$ & Dandong, Liaoning & 2005-2701D & JN162108 & JN162098 & GQ864030 & GQ864091 & GQ864079 & GQ864018 & Clone 2: GQ864049 \\
\hline & & & & & & & & & & & Clone 3: GQ864050 \\
\hline & & & & & & & & & & & Clone 4: GQ864051 \\
\hline \multirow[t]{4}{*}{3} & G. scabra & $\mathrm{GL}$ & Beian, Heilongjiang & $2005-2702 A$ & JN162105 & JN162093 & GQ864027 & GQ864088 & GQ864076 & GQ864015 & Clone 1: GQ864039 \\
\hline & & & & & & & & & & & Clone 2: GQ864040 \\
\hline & & & & & & & & & & & Clone 3: GQ864041 \\
\hline & & & & & & & & & & & Clone 4: GQ864042 \\
\hline \multirow[t]{3}{*}{4} & G. scabra & $\mathrm{GL}$ & Yinan, Heilongjiang & $2005-2702 B$ & JN162106 & JN162094 & GQ864028 & GQ864089 & GQ864077 & GQ864016 & Clone 1: GQ864043 \\
\hline & & & & & & & & & & & Clone 2: GQ864044 \\
\hline & & & & & & & & & & & Clone 4: GQ864045 \\
\hline \multirow[t]{3}{*}{5} & G. triflora & $\mathrm{GL}$ & Yinan, Heilongjiang & $2005-2703 \mathrm{~A}$ & JN162109 & JN162095 & GQ864031 & GQ864092 & GQ864080 & GQ864019 & Clone 1: GQ864052 \\
\hline & & & & & & & & & & & Clone 2: GQ864053 \\
\hline & & & & & & & & & & & Clone 13: GQ864054 \\
\hline \multirow[t]{3}{*}{6} & G. triflora & $\mathrm{GL}$ & Yinan, Heilongjiang & 2005-2703B & JN162110 & JN162096 & GQ864032 & GQ864093 & GQ864081 & GQ864020 & Clone 2: GQ864055 \\
\hline & & & & & & & & & & & Clone 3: GQ864056 \\
\hline & & & & & & & & & & & Clone 4: GQ864057 \\
\hline \multirow[t]{3}{*}{7} & G. rigescens & Jianlongdan (JL) & Deqin, Yunnan & $2005-2704 A$ & JN162111 & JN162099 & GQ864033 & GQ864094 & GQ864082 & GQ864021 & Clone 1: GQ864058 \\
\hline & & & & & & & & & & & Clone 2: GQ864059 \\
\hline & & & & & & & & & & & Clone 32: GQ864060 \\
\hline \multirow[t]{3}{*}{8} & G. rigescens & $J$ & Weishan, Yunnan & $2005-2704 B$ & JN162112 & JN162100 & GQ864034 & GQ864095 & GQ864083 & GQ864022 & Clone 1: GQ864061 \\
\hline & & & & & & & & & & & Clone 2: GQ864062 \\
\hline & & & & & & & & & & & Clone 4: GQ864063 \\
\hline \multirow[t]{2}{*}{9} & G. rhodantha & & Xishui, Guizhou & $2005-2706 \mathrm{~A}$ & JN162113 & JN162101 & GQ864035 & GQ864096 & GQ864084 & GQ864023 & Clone 1: GQ864064 \\
\hline & & & & & & & & & & & Clone 3: GQ864065 \\
\hline \multirow[t]{4}{*}{10} & G. rhodantha & & Shizhu, Chongqing & $2005-2706 B$ & JN162114 & JN162102 & GQ864036 & - & GQ864085 & GQ864024 & Clone 1: GQ864066 \\
\hline & & & & & & & & & & & Clone 2: GQ864067 \\
\hline & & & & & & & & & & & Clone 3: GQ864068 \\
\hline & & & & & & & & & & & Clone 4: GQ864069 \\
\hline
\end{tabular}


Table 1 Samples studied (Continued)

$11 \quad$ P. hexandrum Xiaoyelian

Institute of Chinese Medicine,

ICM686

JN162115 JN162103 GQ864038

GQ864098

GQ864087

GQ864026

The Chinese University of

Clone 2: GQ864071

Hong Kong (ICM-CUHK)

Clone 3: GQ864072

12 P. hexandrum Xiaoyelian

Chinese herbal museum, ICM-CUHK ICM2148

JN162116 JN162104 GQ864037 GQ864097 GQ864086

GQ864025

Clone 1: GQ864073

Clone 3: GQ864074

Clone 4: GQ864075 
gymnosperms, ferns and mosses, respectively. ITS regions can be found in plants, animals and fungi, and occasionally ITS regions of fungi in medicinal materials were co-amplified, thereby making direct sequencing of the amplified DNA product unsuccessful. The nontranscribed spacer of $5 \mathrm{~S}$ rRNA is highly variable, and some studies have illustrated that its resolving power is higher than those of the ITS sequences [8]. In the chloroplast genome, the trnH-psbA spacer is a rapidly evolving region suitable for identification at the species level [9]. Other chloroplast DNA loci, including trnL-F, have been demonstrated to be informative at the generic level [10]. In a recent study, trnL-F has also been used to separate Cardiocrinum giganteum from its variant C. giganteum var. yunnanense and their closely related species [11].

Four medicinal Gentiana species, including Gentiana manshurica Kitag., Gentiana scabra Bunge, Gentiana triflora Pall., and Gentiana rigescens Franch., are listed in the Chinese Pharmacopoeia as Gentianae Radix et Rhizoma or "Longdan" in Chinese [12]. They are common medicinal materials used for treating liver diseases [13], and hepatoprotective against acetaminopheninduced acute toxicity [14]. The first three species are mainly distributed in the northeastern part of China and called "Guanlongdan" (GL), while G. rigescens is located in the southwestern part of China and called "Jianlongdan" (JL). The genus Gentiana is divided into 12 sections in China [15]. GL and JL belong to the adjacent sections of Pneumonanthe (Section III) and Monopodiae (section IV), respectively. While different plant species may be used for the same medicinal purpose in Chinese medicine (e.g. Gentiana rhodantha Franch. is frequently used as a substitute in southwestern China), the neurotoxic Podophyllum hexandrum Royle in the family Berberidaceae with a similar morphology is deemed adulterant [16].

This study aims to evaluate the feasibility and limitations of $r b c L$ and $m a t K$ and five other commonly used DNA regions for authentication of medicinal Gentiana species and their adulterants, $G$. rhodantha and $P$. hexandrum. In particular, the sequence divergences and differentiation powers of the tested regions were determined and compared.

\section{Methods}

Authentic samples were collected from various regions of China, as identified by Dr. Hui Cao based on morphological characters. (Table 1) [17]. The voucher specimens were deposited in the Institute of Chinese Medicine, The Chinese University of Hong Kong.

The rhizome of each sample (0.05 g) was ground and total DNA was extracted by a modified CTAB extraction method with a minor modification [18] that the DNA pellet was resuspended in $30 \mu \mathrm{L}$ of water instead of $50 \mu \mathrm{L}$ of Tris-EDTA buffer. Polymerase chain reaction was performed in a $25-\mu \mathrm{L}$ mixture. Details of the primer sequences and the respective amplified regions are presented in Table 2. The specific PCR products were isolated from the PCR mixture by a Gel-M ${ }^{\mathrm{Tm}}$ Gel Extraction System (Viogene, Taiwan). Except for 5S rRNA, the purified PCR products of the DNA barcodes were directly sequenced. The $5 \mathrm{~S}$ rRNA PCR product was ligated into the pGEM-T Easy vector (Promega, USA) at $25^{\circ} \mathrm{C}$ for 2 hours. Three to four clones containing the insert were sequenced for each individual sample. A Rapid Plasmid Miniprep System (Viogene, Taiwan) was used

Table 2 Universal primers used in this study

\begin{tabular}{|c|c|c|c|}
\hline Gene or spacer region & Primer name & Primer sequence (5' to $\left.3^{\prime}\right)$ & Reference \\
\hline \multirow[t]{2}{*}{$r b c L$} & rbcLaF & ATGTCACCACAAACAGAGACTAAAGC & [4] \\
\hline & rbcLaR & GTAAAATCAAGTCCACCRCG & {$[4]$} \\
\hline \multirow[t]{2}{*}{ matk } & $3 \mathrm{~F} \mathrm{KIM} \mathrm{f}$ & CGTACAGTACTITTGTGTTTACGAG & [4] \\
\hline & $1 \mathrm{R} \mathrm{KIM} \mathrm{r}$ & ACCCAGTCCATCTGGAAATCTTGGTTC & [4] \\
\hline \multirow[t]{2}{*}{$\operatorname{trnH}-p s b A$} & $\operatorname{trnHf}$ & CGCGCATGGTGGATTCACAATCC & [1] \\
\hline & psbA3'f & GTTATGCATGAACGTAATGCTC & [1] \\
\hline \multirow[t]{2}{*}{$\operatorname{trn} L-F$} & Tab C & CGAAATCGGTAGACGCTACG & [22] \\
\hline & Tab F & ATTTGAACTGGTGACACGAG & {$[22]$} \\
\hline \multirow[t]{2}{*}{ rpl36-rps8 } & rpl36f & CACAAATITTACGAACGAAG & [1] \\
\hline & rps8r & TAATGACAGAYCGAGARGCTCGAC & [1] \\
\hline \multirow[t]{2}{*}{ ITS } & ITS5 & GGAAGTAAAAGTCGTAACAAGG & [23] \\
\hline & ITS4 & TCCTCCGCTTATTGATATGC & [23] \\
\hline \multirow[t]{2}{*}{ 5S rRNA } & S1 & GGATCCGTGCTTGGGCGAGAGTAGTA & [24] \\
\hline & AS1 & GGATCCTTAGTGCTGGTATGATCGCA & [24] \\
\hline
\end{tabular}


Table 3 Sequence alignment among the matK forward primer $3 \mathrm{~F} \mathrm{Kim} \mathrm{f}$ and the corresponding binding sites of the Gentiana species available in NCBI

\begin{tabular}{|c|c|c|}
\hline \multirow[t]{3}{*}{ NCBI Accession no. } & \multirow[t]{3}{*}{ Scientific name } & Sequence alignment \\
\hline & & $3 \mathrm{~F} \mathrm{Kim} \mathrm{f}$ sequence ( $5^{\prime}$ to $\left.3^{\prime}\right)$ \\
\hline & & CGTACAGTACTTTTGTGTTTACGAG \\
\hline EF552125.1 & Gentiana acaulis & $\ldots T \ldots A \ldots \ldots \ldots \ldots C \ldots G$. \\
\hline EF552079.1 & Gentiana bavarica & $\ldots T \ldots$. . . \\
\hline EF552115.1 & Gentiana bavarica subsp. subacaulis & $\ldots T \ldots A \ldots \ldots \ldots \subset, G$. \\
\hline EF552117.1 & Gentiana brachyphylla & $\ldots T \ldots$. . . \\
\hline EF552116.1 & Gentiana brachyphylla & $\ldots T \ldots$. . . . . . C.G. \\
\hline EF552100.1 & Gentiana brachyphylla & $\ldots T \ldots$. . . \\
\hline EF552102.1 & Gentiana brachyphylla subsp. favratii & $\ldots$. . . A. . \\
\hline EF552101.1 & Gentiana brachyphylla subsp. favratii & $\ldots T \ldots$. . . . . . . . G. \\
\hline EF552124.1 & Gentiana nivalis & $\ldots T \ldots$. . . \\
\hline EF552123.1 & Gentiana nivalis & $\ldots T \ldots$. . . . . . . . \\
\hline EF552122.1 & Gentiana nivalis & $\ldots T \ldots$. . . \\
\hline EF552121.1 & Gentiana nivalis & $\ldots \mathrm{T} \ldots$. . . . \\
\hline EF552126.1 & Gentiana prostrata & $\ldots . T$. A.T. \\
\hline EF552120.1 & Gentiana pumila & $\ldots T \ldots A \ldots \ldots \ldots \subset, G$ \\
\hline EF552086.1 & Gentiana pumila subsp. delphinensis & $\ldots T \ldots$. . . \\
\hline EF552085.1 & Gentiana pumila subsp. delphinensis & $\ldots T \ldots$. . . . . . C.G. \\
\hline EF552114.1 & Gentiana rostanii & $\ldots$. . . А. . \\
\hline EF552113.1 & Gentiana rostanii & $\ldots$. T. . . . \\
\hline EF552078.1 & Gentiana terglouensis & $\ldots T \ldots A \ldots \ldots \ldots, C \ldots$ \\
\hline EF552107.1 & Gentiana terglouensis subsp. schleicheri & $\ldots$.... A. . \\
\hline EF552087.1 & Gentiana terglouensis subsp. schleicheri & $\ldots$. . . A. . \\
\hline EF552119.1 & Gentiana utriculosa & $\ldots T \ldots$. . . \\
\hline EF552118.1 & Gentiana utriculosa & $\ldots \mathrm{T} \ldots$ A. . . \\
\hline EF552105.1 & Gentiana verna & $\ldots T \ldots$. . . . . . . . G. \\
\hline EF552104.1 & Gentiana verna & $\ldots T \ldots$. . . . . . . . . \\
\hline EF552103.1 & Gentiana verna & $\ldots T \ldots$. . . \\
\hline EF552099.1 & Gentiana verna & $\ldots T \ldots A \ldots \ldots \ldots, \ldots, G$. \\
\hline EF552098.1 & Gentiana verna & $\ldots T$. A. \\
\hline EF552097.1 & Gentiana verna & $\ldots T \ldots$. . . \\
\hline EF552096.1 & Gentiana verna & $\ldots T \ldots A \ldots \ldots \ldots, C \ldots G$. \\
\hline EF552111.1 & Gentiana verna subsp. balcanica & $\ldots T \ldots$. . . . \\
\hline EF552106.1 & Gentiana verna subsp. balcanica & $\ldots \mathrm{T}, \mathrm{A} \ldots \ldots \ldots \ldots, \mathrm{C}, \mathrm{G}$. \\
\hline EF552112.1 & Gentiana verna subsp. pontica & $\ldots T$. A. . \\
\hline EF552110.1 & Gentiana verna subsp. pontica & $\ldots T \ldots A \ldots \ldots \ldots, C \ldots G$. \\
\hline EF552109.1 & Gentiana verna subsp. pontica & $\ldots T \ldots A \ldots \ldots \ldots, C \ldots$. \\
\hline EF552108.1 & Gentiana verna subsp. tergestina & $\ldots T \ldots$. . . . . . C.G. \\
\hline
\end{tabular}

Gentiana sequences downloaded from GenBank were converted into their reverse complement before alignment against $3 \mathrm{~F}$ Kim $\mathrm{f}$.

for plasmid extraction. The purified PCR products or plasmids were sequenced using a BigDye ${ }^{\bullet}$ Terminator v3.1 Cycle Sequencing Kit (Applied Biosystems, USA). Alignment of the DNA sequences was accomplished by ClustalW using the BioEdit program [19,20], and manual adjustment of the sequence alignment was performed if necessary. The genetic distance among samples was determined by the nucleotide model Kimura 2-parameter in MEGA 5 software [21]. All distances were calculated from pairwise global alignments, in which alignment 
gaps and missing data were eliminated by choosing the "pairwise deletion option". If the minimum sequence divergence between two groups of species was larger than the maximum intraspecific sequence divergence of the two groups of species, the discrimination was considered successful. Phylogenetic trees of the seven loci were constructed by MEGA5 with the neighbor-joining (NJ) method [21]. Bootstrap analyses for 1000 replicates were performed to provide confidence estimates for the tree topologies.

\section{Results}

\section{DNA barcode sequence determination}

The primers listed in Table 2 could amplify the corresponding loci in the samples, except for the trnL-F region of sample 2005-2706b (G. rhodantha) and the matK regions of samples 2005-2703b (G. triflora), 20052704a (G. rigescens), 2005-2704b (G. rigescens), 2005- 2706a (G. rhodantha), ICM 686 (P. hexandrum) and ICM 2148 ( $P$. hexandrum). As a result, we checked the complementarity between the primers and the available Gentiana sequences from National Center for Biotechnology information (NCBI). For matK, it was found that there are 3-4 different nucleotides between $3 \mathrm{~F}$ KIM $\mathrm{f}$ and the Gentiana sequences (Table 3). We designed a new pair of primers, matK_G SC_F (5'-TATATATTG TATTCGATACAAAC-3') and matK_GSC_R (5'-TTC TACGAATATTGGAATTGGAA-3'), based on the conserved region of the available Gentiana and $P$. hexan drum sequences, which successfully amplified all of the Gentiana and $P$. hexandrum samples. For trnL-F, there was only one nucleotide difference near the $5^{\prime}$ end terminus of the primer. Since only sample 2005-2706b (G. rhodantha) could not be amplified, the failure of amplification might be caused by fragmentation of the template DNA.

Table 4 Properties of the seven barcoding regions of Gentiana and $P$. hexandrum

\begin{tabular}{|c|c|c|c|c|c|c|c|c|}
\hline Property & Species & $r b c L$ & matK & $\operatorname{trnH}-p s b A$ & $\operatorname{trn} L-F$ & rpl36-rps8 & ITS & 5S rRNA \\
\hline \multirow[t]{6}{*}{ Average length (bp) } & G. manshurica & 553.0 & 716.0 & 482.5 & 760.5 & 319.0 & 693.0 & 455.3 \\
\hline & G. scabra & 553.0 & 716.0 & 482.5 & 759.0 & 319.0 & 693.0 & 455.6 \\
\hline & G. triflora & 553.0 & 716.0 & 482.0 & 762.5 & 319.0 & 693.0 & 456.7 \\
\hline & G. rigescens & 553.0 & 716.0 & 399.0 & 820.0 & 317.0 & 694.0 & 260.5 \\
\hline & G. rhodantha & 553.0 & 716.0 & 411.0 & 820.0 & 304.0 & 691.0 & 240.3 \\
\hline & P. hexandrum & 553.0 & 716.0 & 646.0 & 940.0 & 524.0 & 703.5 & 267.3 \\
\hline \multirow[t]{6}{*}{ GC content (\%) } & G. manshurica & 43.8 & 33.4 & 24.0 & 38.7 & 32.0 & 58.4 & 45.7 \\
\hline & G. scabra & 43.8 & 33.5 & 24.0 & 38.6 & 32.0 & 58.6 & 45.0 \\
\hline & G. triflora & 43.8 & 33.3 & 24.0 & 38.5 & 32.0 & 58.7 & 46.6 \\
\hline & G. rigescens & 43.5 & 33.5 & 27.5 & 36.7 & 30.0 & 58.4 & 49.7 \\
\hline & G. rhodantha & 43.4 & 33.2 & 26.5 & 34.4 & 32.0 & 57.6 & 53.7 \\
\hline & P. hexandrum & 42.9 & 34.4 & 26.0 & 34.4 & 37.0 & 51.0 & 41.5 \\
\hline \multirow[t]{15}{*}{ Selected polymorphic site* } & & 12233 & 1125 & 144 & 12599 & 1124 & 244 & 12234 \\
\hline & & 05689 & 660128 & 56101 & 315966 & 551248 & 378418 & 3954472 \\
\hline & & 666487 & 137062 & 840187 & 895856 & 066664 & 560905 & 9578946 \\
\hline & G. manshurica & TCATAA & GTGGAC & TGAATT & ACGCAC & CCCCAG & GTAGCT & CCATGGG \\
\hline & & TCATAA & GTGGAC & TGAATT & ACGCAC & CCCCAG & GTAGCT & CCATGGG \\
\hline & G. scabra & TCATAA & GTGGAC & TGAATT & ACGCGA & CCCCAG & GTAGCT & CCATGGG \\
\hline & & TCATAA & GTGGAC & TGAATT & ACGCGA & CCCCAG & GTAGCT & CCATGGG \\
\hline & G. triflora & TCATAA & GTGGAC & TGAATT & ACGCAC & CCCCAG & GTAGCT & CCGAATC \\
\hline & & TCATAA & GTGGAC & TGAATT & ACGCAC & CCCCAG & GTAGCT & CCGAATC \\
\hline & G. rigescens & TTAAAG & ACGGGG & TGGCAT & ACAGGA & CATTTG & GTGACG & C-G--CT \\
\hline & & TTAAAG & ACGGGG & TGGCAT & ACAGGA & CATTTG & GTGACG & C-G- - CT \\
\hline & G. rhodantha & TTGAGA & GTAGGC & TAGAAG & ATATGA & TCСТTC & GCTGTC & CTT- - T- \\
\hline & & TTGAGA & GTAGGC & TAGAAG & N/A & TCСТTC & GCTGTC & CTT- - T- \\
\hline & P. hexandrum & CTCAGT & TTAAAT & CCGATT & GGAGGA & ACCTAA & ACTGCA & TTA - - TT \\
\hline & & CTCAGT & TTAAAT & CCGATT & GGAGGA & ACCTAA & ACTGCA & TTA - - TT \\
\hline
\end{tabular}

*The polymorphic site positions are shown in a vertical manner. For example, the first polymorphic site of $r b c L$ is 6 , and the second one is 106 .

The numbers above the polymorphic sites are their positions in the multiple sequence alignment. ' - ' in the alignment represents a gap in the DNA sequence. 
Table 5 Sequence divergence of the seven barcoding regions of Gentiana and $P$. hexandrum

\begin{tabular}{|c|c|c|c|c|c|c|c|}
\hline & $r b c L$ & matK & trnH-psbA & $\operatorname{trn} L-F$ & rp/36-rps8 & ITS & 5S rRNA \\
\hline \multicolumn{8}{|l|}{ (1) Comparison between (A) Medicinal Gentiana \& (B) P. hexandrum } \\
\hline i) Minimum sequence divergence between Medicinal Gentiana \& $P$. hexandrum & 0.0995 & 0.3399 & 0.3908 & 0.3888 & 0.2211 & 0.4781 & 0.6154 \\
\hline ii) Maximum intraspecific divergence among Medicinal Gentiana \& $P$. hexandrum & 0.0018 & 0.0042 & 0.0101 & 0.0026 & 0.0033 & 0.0058 & 0.0939 \\
\hline iii) Can this barcode distinguish these two groups? \# & Yes & Yes & Yes & Yes & Yes & Yes & Yes \\
\hline iv) Differentiation power ranking ${ }^{*}$ & 7 & 5 & 3 & 4 & 6 & 2 & 1 \\
\hline \multicolumn{8}{|l|}{ (2) Comparison between (A) Medicinal Gentiana \& (B) G. rhodantha } \\
\hline i) Minimum sequence divergence between Medicinal Gentiana \& G. rhodantha & 0.0128 & 0.0597 & 0.1349 & 0.1562 & 0.0958 & 0.0862 & 0.3098 \\
\hline ii) Maximum intraspecific divergence among Medicinal Gentiana \& G. rhodantha & 0.0018 & 0.0042 & 0.0101 & 0.0026 & 0.0033 & 0.0058 & 0.0914 \\
\hline iii) Can this barcode distinguish these two groups? ${ }^{\#}$ & Yes & Yes & Yes & Yes & Yes & Yes & Yes \\
\hline iv) Differentiation power ranking ${ }^{*}$ & 7 & 6 & 3 & 2 & 4 & 5 & 1 \\
\hline \multicolumn{8}{|l|}{ (3) Comparison between (A) Guanlongdan \& (B) Jianlongdan } \\
\hline i) Minimum sequence divergence between Guanlongdan \& Jianlongdan & 0.0109 & 0.0521 & 0.0780 & 0.0332 & 0.0392 & 0.0462 & 0.4897 \\
\hline ii) Maximum intraspecific divergence among Guanlongdan \& Jianlongdan & 0.0018 & 0.0042 & 0.0101 & 0.0026 & 0.0000 & 0.0043 & 0.0914 \\
\hline iii) Can this barcode distinguish these two groups? ${ }^{\#}$ & Yes & Yes & Yes & Yes & Yes & Yes & Yes \\
\hline iv) Differentiation power ranking ${ }^{*}$ & 7 & 3 & 2 & 6 & 5 & 4 & 1 \\
\hline
\end{tabular}

"Barcode is able to distinguish the two groups if (i) $>$ (ii).

*The differentiation power ranking was determined by (i). The most varied locus was ranked as 1 and the least varied locus was ranked as 7 .

\section{Sequence divergences of the seven DNA regions}

The sizes of the seven loci (excluding the primerbinding sites) of the examined species are shown in Table 4. The sizes ranged from 239 to $940 \mathrm{bp}$, with most falling between 400 to $800 \mathrm{bp}$ as the optimum range for routine PCR. The lengths of the protein-encoding genes $r b c L$ and $m a t K$ were identical across the samples, while the five intergenic spacers were found to be varied.

To show the discriminative powers of the seven DNA regions, we compared the sequence divergence of (1) medicinal Gentiana species (G. scabra, G. manshurica, G. triflora and G. rigescens) and their adulterants ( $G$. rhodantha and P. hexandrum); and (2) GL (G. scabra, G. manshurica and G. triflora) and JL (G. rigescens)
(Table 5). When comparing the divergences between medicinal Gentiana species and their adulterants, 5S rRNA had the highest divergence values, both interspecifically and intraspecifically, while $r b c L$ had the lowest values (Table 5). The minimum divergence values of $r b c L, m a t K, t r n H-p s b A, t r n L-F$, rpl36-rps8, ITS and 5S rRNA between medicinal Gentiana and $P$. hexandrum were $0.0995,0.3399,0.3908,0.3888,0.2211,0.4781$ and 0.6154 , while the maximum intraspecific divergence values were only $0.0018,0.0042,0.0101,0.0026,0.0033$, 0.0058 and 0.0939, respectively. For medicinal Gentiana and the adulterant $G$. rhodantha, the minimum divergence values between these regions were 0.0128, 0.0597, $0.1349,0.1562,0.0958,0.0862$ and 0.3098 , while the

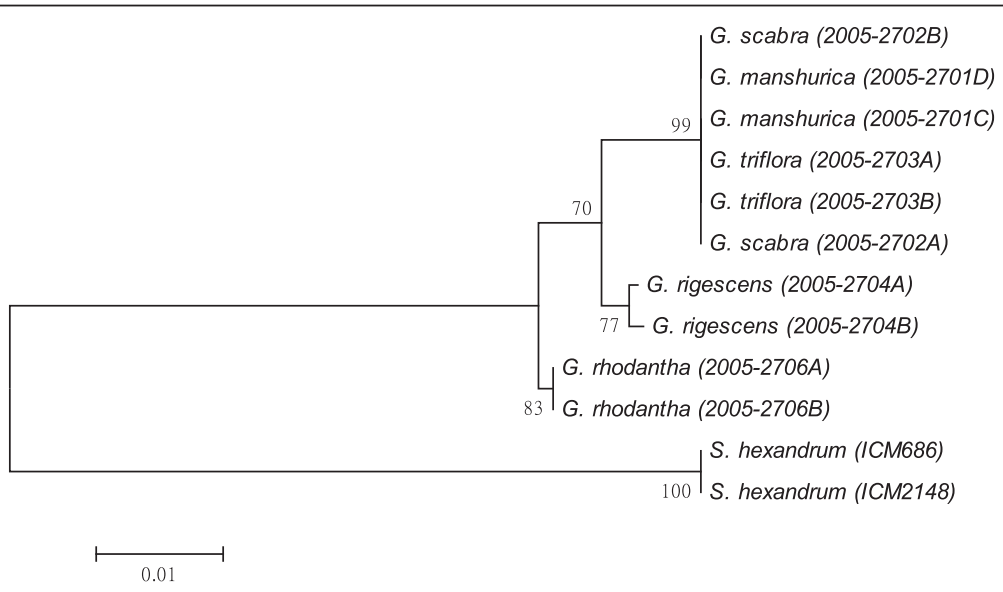

Figure 1 K2P distance NJ tree for rbcL. A consensus NJ tree for rbcL of Gentiana and $P$. hexandrum assessed with 1000 bootstrap replicates was constructed by bootstrap analyses with the bootstrap values indicated at the branches (bootstrap values of less than 50 are not shown). 


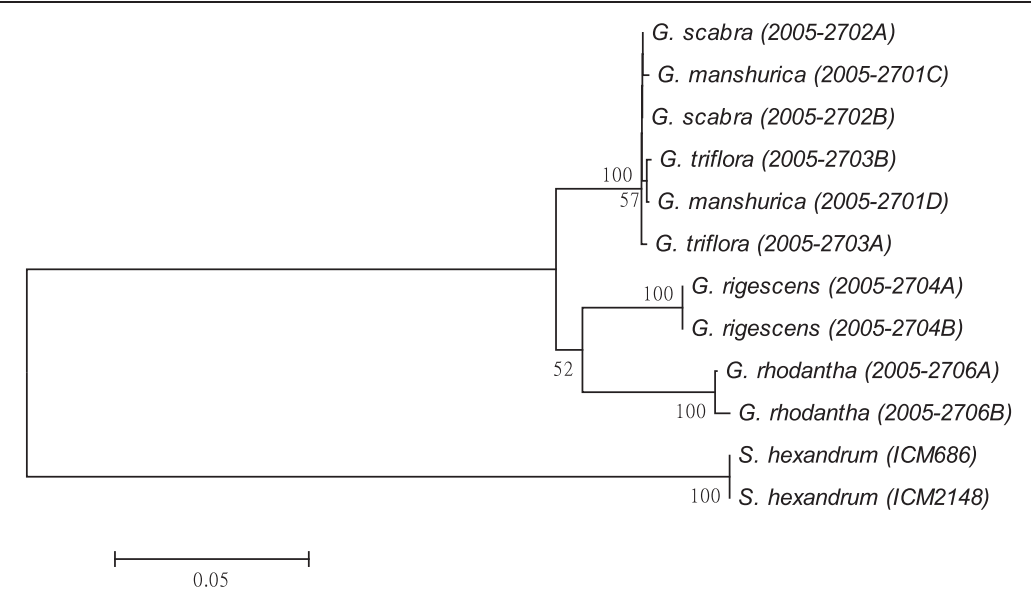

Figure 2 K2P distance NJ tree for matK. A consensus NJ tree for matK of Gentiana and $P$. hexandrum assessed with 1000 bootstrap replicates was constructed by bootstrap analyses with the bootstrap values indicated at the branches (bootstrap values of less than 50 are not shown).

maximum intraspecific divergence values were 0.0018 , $0.0042,0.0101,0.0026,0.0033,0.0058$ and 0.0914 , respectively. Since the maximum intraspecific divergences of the seven loci were lower than the interspecific divergences, all of them could be employed to discriminate between medicinal Gentiana species and their adulterants.

The DNA sequences were significantly different in GL and JL. The minimum divergence values of $r b c L$, matK, trnH-psbA, trnL-F, rpl36-rps8, ITS and 5S rRNA between these two groups were 0.0109, 0.0521, 0.0780, $0.0332,0.0392,0.0462$ and 0.4897 , while the maximum intraspecific divergence values were $0.0018,0.0042$, $0.0101,0.0026,0.0000,0.0043$ and 0.0914 , respectively. Therefore, GL and JL could be distinguished from each other using any of the seven DNA loci (Table 5). On the other hand, the genetic variability in the three GL species was extremely low for all loci. Only $5 \mathrm{~S}$ rRNA could differentiate between G. manshurica and G. triflora, while trnL-F could distinguish G. scabra and G. triflora. Table 4 shows the selected polymorphic sites for differentiating among the three GL species. G. triflora, G. scabra and G. manshurica are genetically closely related, and possess the interchangeable medicinal applications.

To confirm the effectiveness of $r b c L$ and matK in the identification of Gentiana species, we included all available Gentiana sequences in NCBI in the analysis of these two barcodes. In total, $14 \mathrm{rbcL}$ sequences (including 10 sequences generated in this study) of 9 Gentiana species and 68 mat $K$ sequences (including 10 sequences generated in this study) of 23 Gentiana species and subspecies were aligned. For $r b c L$, the maximum intraspecific divergence value was 0.00215 , while the minimum interspecific divergence value was 0 . We found that the rbcL sequences of Gentiana andrewsii (HQ590117.1)

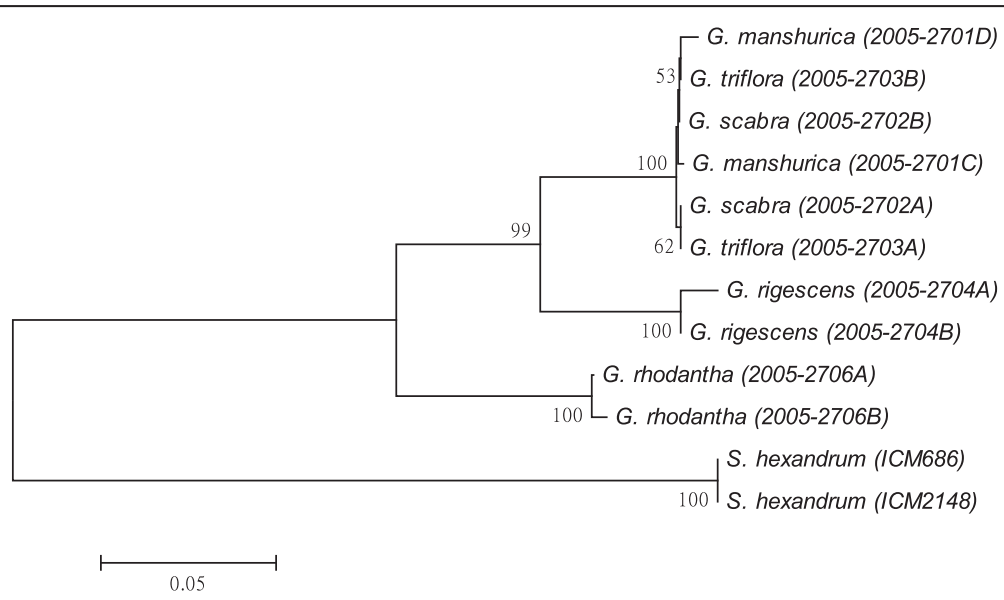

Figure $3 \mathrm{~K} 2 \mathrm{P}$ distance NJ tree for trnH-psbA. A consensus NJ tree for trnH-psbA of Gentiana and P. hexandrum assessed with 1000 bootstrap replicates was constructed by bootstrap analyses with the bootstrap values indicated at the branches (bootstrap values of less than 50 are not shown). 


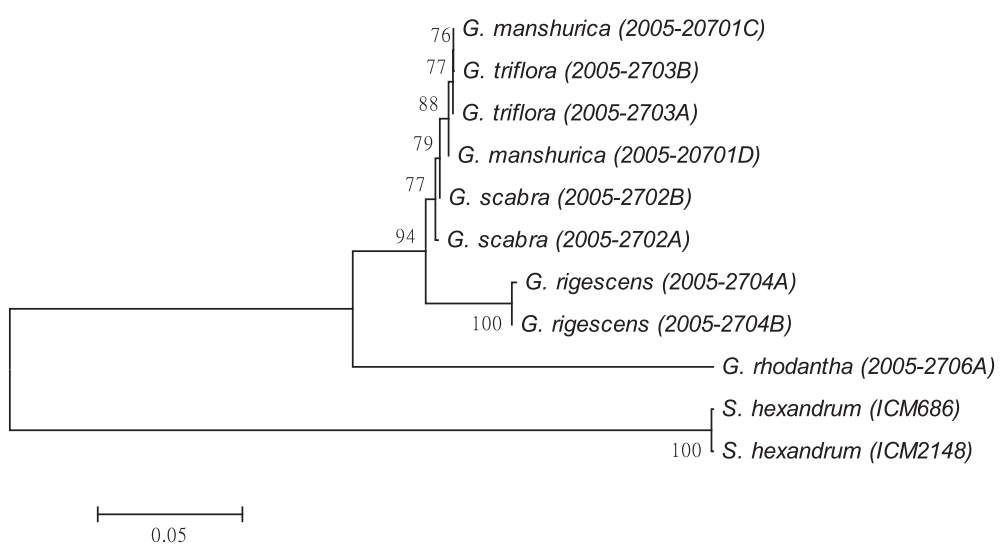

Figure $4 \mathrm{~K} 2 \mathrm{P}$ distance $\mathrm{NJ}$ tree for trnL-F. A consensus NJ tree for trnL-F of Gentiana and P. hexandrum assessed with 1000 bootstrap replicates was constructed by bootstrap analyses with the bootstrap values indicated at the branches (bootstrap values of less than 50 are not shown).

and Gentiana pneumonathe (JN891473.1) were identical. For $m a t K$, the maximum intraspecific divergence value was 0.01032, while the minimum interspecific divergence value was 0 . Twenty sequences were identical, including 12 samples of Gentiana verna (EF552088. 1-EF552099.1), one sample of Gentiana schleicheri (EF552087.1), three samples of Gentiana pumila subsp. delphinensis (EF552084.1-EF552086.1) and four samples of Gentiana brachyphylla subsp. favratii (EF552080.1EF552083.1). These results indicated that $r b c L$ and matK could not resolve all Gentiana species well.

As shown in Figures 1, 2, 3, 4, 5, 6 and 7, the NJ trees of the seven barcodes revealed that medicinal Gentiana species were clearly differentiated from $P$. hexandrum. Among the Gentiana species, the three GL species were clustered together as a clade and separated from JL and G. rhodantha with high supporting bootstrap values $(>70 \%)$, suggesting that the species identification among
GL, JL and G. rhodantha can be well resolved by the seven DNA barcodes.

\section{Discussion}

This study performed a comparative assessment of the discriminative powers of seven DNA regions for the authentication of genetically closely related medicinal Gentiana species and their adulterants. $r b c L$ and matK are the two recommended DNA barcodes that can resolve $72 \%$ of land plants when used in combination [4]. In our study, however, $r b c L$ provided the lowest intraspecific and interspecific divergences. There were only 6 bp that differed out of $553 \mathrm{bp}$ between GL and JL. It has also been shown that $r b c L$ is the least divergent locus among 11 DNA barcode candidates for differentiating species in Solanaceae [1].

The other CBOL-recommended barcode matK had higher sequence divergence, but was difficult to amplify

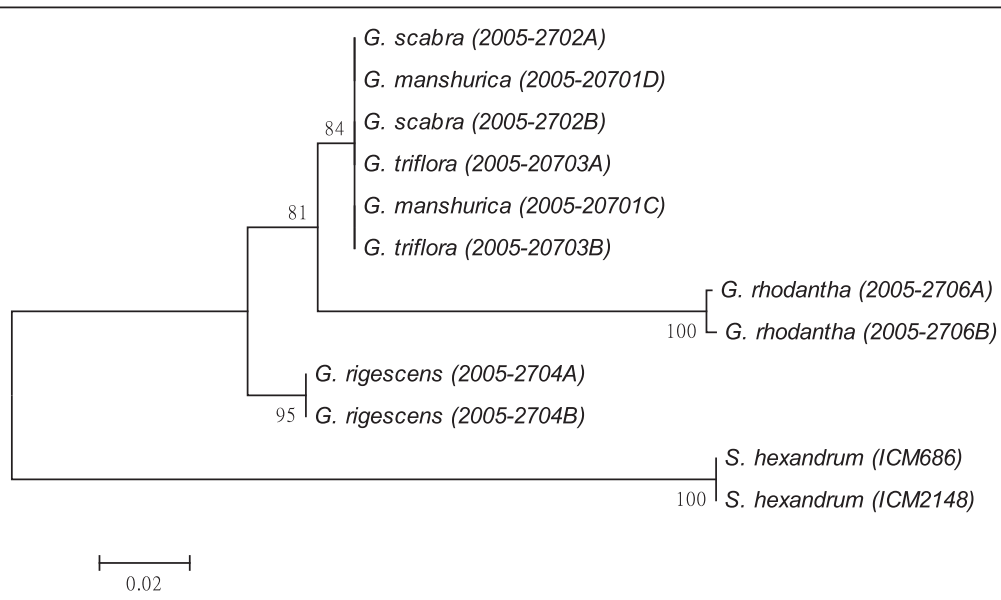

Figure 5 K2P distance NJ tree for rpl36-rps8. A consensus NJ tree for rp/36-rps8 of Gentiana and P. hexandrum assessed with 1000 bootstrap replicates was constructed by bootstrap analyses with the bootstrap values indicated at the branches (bootstrap values of less than 50 are not shown). 


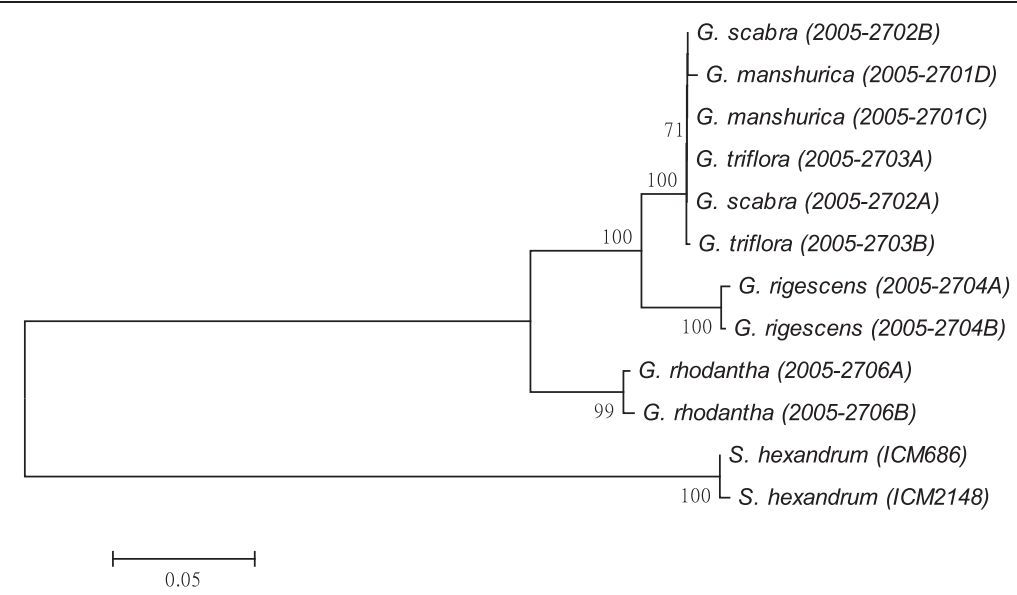

Figure 6 K2P distance NJ tree for ITS. A consensus NJ tree for ITS of Gentiana and P. hexandrum assessed with 1000 bootstrap replicates was constructed by bootstrap analyses with the bootstrap values indicated at the branches (bootstrap values of less than 50 are not shown).

by PCR. There were mismatches between the primer and the published Gentiana sequences, indicating that the recommended matK primers might not be applicable to all land plants. A recent study of medicinal plants in Southern Morocco [25] shows that the success rate of PCR amplification of matK is less than 30\%. Regarding the resolving power, mat $K$ had the third-highest value for differentiating between GL and JL (Table 5). Nevertheless, it was only ranked fifth and sixth for distinguishing between medicinal Gentiana species and their adulterants $P$. hexandrum and G. rhodantha, respectively.

trnL-F had the longest DNA sequence among the tested loci (Table 4). A Gentiana sample could not be amplified, which was probably due to fragmentation of the DNA or other reasons. trnL-F had a high resolving power, and was the only locus capable of differentiating G. scabra from G. triflora (Table 4), suggesting trnL-F as a good locus for differentiation of the closely related Gentiana species.

The size of rpl36-rps8 was small among the seven loci (Table 4) The PCR product of $P$. hexandrum was about 200 bp larger than those of Gentiana. Thus, the size difference could be used as a marker to distinguish Gentiana from $P$. hexandrum without DNA sequencing. Like $r b c L$, rpl36-rps 8 also had low interspecific and intraspecific divergences, although its ranking was slightly higher than that of $r b c L$. Its major drawback was the limited number of reference sequences in GenBank.

The size of the trnH-psbA region ranged from 399 to $646 \mathrm{bp}$, which was moderate among the seven DNA regions (Table 4). There was a significant size difference between Gentiana and Podophyllum. In terms of the resolving power, trnH-psbA had ranked second for differentiating GL from JL, and provided higher resolving power than matK and $r b c L$. This intergenic spacer also shows a good amplification success rate and discrimination power among the nine loci tested [1]. Among 19 species in seven families of angiosperms, trn $H-p s b A$ shows nearly three-fold higher divergence than other tested chloroplast regions, while the ITS region exhibits two-fold higher divergence than trnH-psbA [1].

Some studies [26-28] show that nuclear ITS is an appropriate DNA marker for herbal authentication and plant phylogenetic studies. In our study, the ITS region was the third longest region across Gentiana and P. hexandrum, and the sizes differed slightly from one another (Table 4). The divergence ranking was average among the five Gentiana species, but increased to the second highest for distinguishing medicinal Gentiana and P. hexandrum (Table 5), indicating that the ITS regions among the studied Gentiana species were quite conserved.

The size of the 5S rRNA intergenic spacer regions ranged from 239 to $457 \mathrm{bp}$, which was the smallest but most varied (Table 4). Among the tested regions, only $5 \mathrm{~S}$ rRNA could distinguish G. triflora from G. manshurica and G. scabra. Our study showed that the intraspecific divergence was high, which was probably due to the non-homogeneity of the different copies of the 5S rRNA gene spacer. It is essential to clone the amplified PCR product prior to sequencing to overcome the sequence degeneration issue.

Jiang et al. [29] established chemical profiles of Gentiana species. The four medicinal Gentiana species involved have close similarity in their chemical compositions, in that they all contain loganic acid, 6-OB-D-glucopyranosylgentiopicroside, swertiamarin, gen tiopicroside, and sweroside [29]. Compound 2-(o,mdihydroxybenzyl)-sweroside is only found in G. rigescens [29] and can be used to differentiate GL and JL. Among the three GL species, only G. triflora contains gentiotrifloroside [29]. The chemical profiles of $G$. 


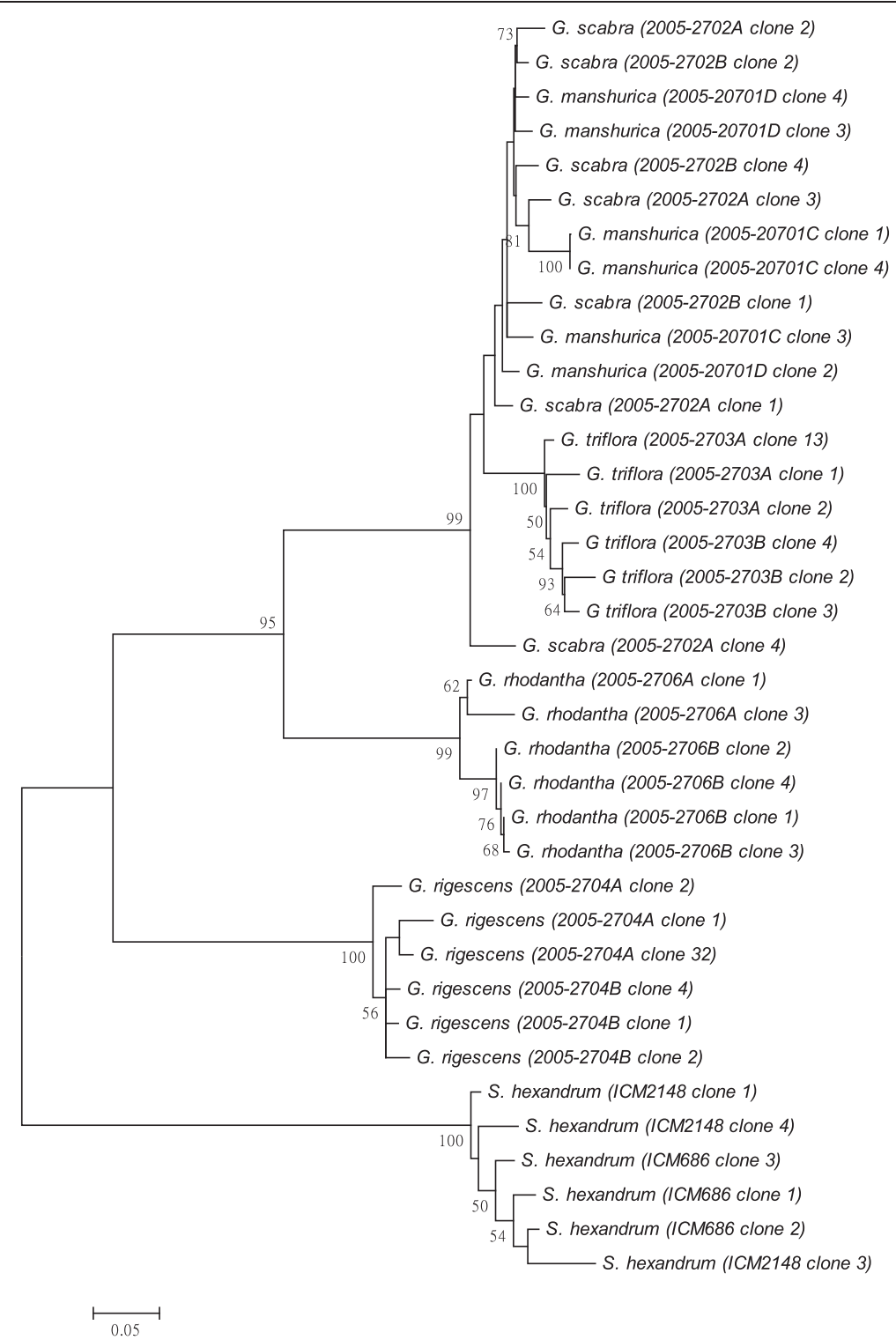

Figure 7 K2P distance NJ tree for 5S rRNA. A consensus NJ tree for $5 S$ rRNA of Gentiana and P. hexandrum assessed with 1000 bootstrap replicates was constructed by bootstrap analyses with the bootstrap values indicated at the branches (bootstrap values of less than 50 are not shown).

manshurica and G. scabra are nearly identical, except that the former has a higher sweroside content [29]. The chemical profiles therefore support our observations in the DNA barcode analyses.

\section{Conclusion}

All the tested loci could differentiate medicinal Gentiana species from their adulterants, and distinguish GL from JL. The two official DNA barcodes, $r b c L$ and matK, have no significant advantages over the remaining five loci examined.

\section{Abbreviations}

CBOL: Consortium for the Barcode of Life; GL: Guanlongdan; JL: Jianlongdan; NCBI: National Center for Biotechnology Information.

\section{Competing interests}

The authors declare that they have no competing interests.

\section{Authors' contributions}

KLW generated the DNA barcode sequences and performed data analyses. PPHB collected herbal materials and designed the study. PCS coordinated the study. KLW and PCS wrote the manuscript. All authors read and approved the final manuscript.

\section{Acknowledgement}

This research was supported by the Strategic Investment Scheme Fund (Scheme A) of the Chinese University of Hong Kong.

Received: 28 February 2013 Accepted: 18 August 2013 Published: 20 August 2013 


\section{References}

1. Kress WJ, Wurdack JK, Zimmer EA, Weigt LA, Janzen DH: Use of DNA barcodes to identify flowering plants. Proc Natl Acad Sci USA 2005, 102:8369-8374

2. Schoch $C L$, Seifert KA, Huhndorf S, Robert V, Spouge JL, Levesque CA, Chen W, Fungal Barcoding Consortium: Nuclear ribosomal internal transcribed spacer (ITS) region as a universal DNA barcode marker for Fungi. Proc Natl Acad Sci USA 2012, 109:6241-6246.

3. Consortium for the Barcode of Life. http://www.barcodeoflife.org/.

4. CBOL Plant Working Group: A DNA barcode for land plants. Proc Natl Acad Sci USA 2009, 106:12794-12797.

5. Ren $B Q$, Xiang XG, Chen ZD: Species identification of Alnus (Betulaceae) using nrDNA and cpDNA genetic markers. Mol Ecol Resour 2010, 10:594-605.

6. Li M, Cao H, But PPH, Shaw PC: Identification of herbal medicinal materials using DNA barcodes. J Syst Evol 2011, 49:271-283.

7. Yao H, Song J, Liu C, Luo K, Han J, Li Y, Pang X, Xu H, Zhu Y, Xiao P, Chen S: Use of ITS2 region as the universal DNA barcode for plants and animals. PLoS One 2010, 5:e13102.

8. Cronn RC, Zhao X, Paterson AH, Wendel JF: Polymorphism and concerted evolution in a tandemly repeated gene family: $5 S$ ribosomal DNA in diploid and allopolyploid cottons. J Mol Evol 1996, 42:685-705.

9. Kondo K, Shiba M, Yamaji H, Morota T, Zhengmin C, Huixia P, Shoyama Y: Species identification of licorice using nrDNA and cpDNA genetic markers. Biol Pharm Bull 2007, 30:1497-1502.

10. Kohjyouma M, Lee IJ, lida O, Kurihara K, Yamada K, Makino Y, Sekita S, Satake M: Intraspecific variation in Cannabis sativa $\mathrm{L}$. based on intergenic spacer region of chloroplast DNA. Biol Pharm Bull 2000, 23:727-730.

11. Li M, Ling KH, Lam H, Shaw PC, Cheng L, Techen N, Khan LA, Chang YS, But PP: Cardiocrinum seeds as a replacement for Aristolochia fruits in treating cough. J Ethnopharmacol 2010, 130:429-432.

12. The Pharmacopoeia Editorial Committee: Pharmacopoeia of the People's Republic of China. Beijing: Chemical Industry Press; 2010.

13. Anonymous: Zhong Yao Zhi. Beijing: The People's Medical publishing House; 1988.

14. Wang AY, Lian LH, Jiang YZ, Wu YL, Nan JX: Gentiana manshurica Kitagawa prevents acetaminophen-induced acute hepatic injury in mice via inhibiting JNK/ERK MAPK pathway. World J Gastroentero/ 2010, 16:384-391.

15. He TN: Gentianaceae Dictionary of Chinese Botany. Beijing: Science Press; 1988.

16. But PP, Tomlinson B, Cheung KO, Yong SP, Szeto ML, Lee CK: Adulterants of herbal products can cause poisoning. BMJ 1996, 313:117.

17. Jiangsu New Medical College: Zhong Yao Da Ci Dian. Shanghai: Shanghai Science and Technology Publishing House; 1977.

18. Kang HW, Cho YG, Yoon UH, Eun MY: A rapid DNA extraction method for RFLP and PCR analysis from a single dry seed. Plant Mol Biol Rep 1998, 16:1-9.

19. Thompson JD, Higgins DG, Gibson TJ: CLUSTAL W: improving the sensitivity of progressive multiple sequence alignment through sequence weighting, position-specific gap penalties and weight matrix choice. Nucleic Acids Res 1994, 22:4673-4680.

20. Hall TA: BioEdit: a user-friendly biological sequence alignment editor and analysis program for Windows 95/98/NT. Nucleic Acids Symp Ser 1999, 41:95-98.

21. Tamura K, Peterson D, Peterson N, Stecher G, Nei M, Kumar S: MEGA5: molecular evolutionary genetics analysis using maximum likelihood, evolutionary distance, and maximum parsimony methods. Mol Biol Evol 2011, 28:2731-2739.

22. Taberlet $P$, Gielly L, Pautou G, Bouvet J: Universal primers for amplification of three non-coding regions of chloroplast DNA. Plant Mol Biol 1991, 17:1105-1109.

23. White TJ, Burns T, Lee S, Taylor J: PCR Protocols: A Guide to Methods and Applications. San Diego: Academic Press; 1990

24. Carles M, Lee T, Moganti S, Lenigk R, Tsim KWK, Ip NY, Hsing IM, Sucher NJ: Chips and Qi: microcomponent based analysis in traditional Chinese medicine. Fresenius J Anal Chem 2001, 371:190-194

25. Kool A, de Boer HJ, Krüger A, Rydberg A, Abbad A, Björk L, Martin G: Molecular identification of commercialized medicinal plants in southern Morocco. PLoS One 2012, 7:e39459.

26. Lau DTW, Shaw PC, Wang J, But PPH: Authentication of medicinal Dendrobium species by the internal transcribed spacer of ribosomal DNA. Planta Med 2001, 67:456-460.

27. Kitaoka F, Kakiuchi N, Long CF, Itoga M, Mitsue A, Mouri C, Mikage M: Molecular characterization of Akebia plants and the derived traditional herbal medicine. Biol Pharm Bull 2009, 32:665-670.
28. Li M, Jiang RW, Hon PM, Cheng L, Li LL, Zhou JR, Shaw PC, But PPH: Authentication of the anti-tumor herb Baihuasheshecao with bioactive marker compounds and molecular sequences. Food Chem 2010, 119:1239-1245

29. Jiang RW, Wong KL, Chan YM, Xu HX, But PPH, Shaw PC: Isolation of iridoid and secoiridoid glycosides and comparative study on Radix Gentianae and related adulterants by HPLC analysis. Phytochemistry 2005, 66:2674-2680.

doi:10.1186/1749-8546-8-16

Cite this article as: Wong et al:: Evaluation of seven DNA barcodes for differentiating closely related medicinal Gentiana species and their adulterants. Chinese Medicine 2013 8:16.

\section{Submit your next manuscript to BioMed Central and take full advantage of:}

- Convenient online submission

- Thorough peer review

- No space constraints or color figure charges

- Immediate publication on acceptance

- Inclusion in PubMed, CAS, Scopus and Google Scholar

- Research which is freely available for redistribution

Submit your manuscript at www.biomedcentral.com/submit
C BioMed Central 